\title{
Discussion on the General Practice Initial Diagnosis Model Based on Process Thinking
}

\author{
Xurui Li, Hui Guo, Ning Xu, Jianguo Li* \\ Department of General Practice, Hebei General Hospital, Shijiazhuang, China \\ Email: *lijg6510@163.com
}

How to cite this paper: Li, X.R., Guo, H., $\mathrm{Xu}, \mathrm{N}$. and Li, J.G. (2020) Discussion on the General Practice Initial Diagnosis Model Based on Process Thinking. Open Journal of Internal Medicine, 10, 342-349. https://doi.org/10.4236/ojim.2020.104036

Received: November 9, 2020

Accepted: December 6, 2020

Published: December 9, 2020

Copyright (c) 2020 by author(s) and Scientific Research Publishing Inc. This work is licensed under the Creative Commons Attribution International License (CC BY 4.0).

http://creativecommons.org/licenses/by/4.0/

\section{(c) (i) Open Access}

\begin{abstract}
It is challenging for general practitioners to make a more correct diagnosis with the least instrument examination. How to make an effective diagnosis has always been an issue. In order to achieve this goal, a clinical symptom-oriented modular diagnosis scheme based on the concept of the process thinking and Murtaghs General Practice was developed for general practitioners. Five key steps according to the workflow of real reception patients by a general practitioner were promulgated in this design of a modular scheme, which is in line with the actual clinical setting. This thinking concept of diagnosis should help prevent missed and erroneous diagnoses and meet the actual needs of general practitioners.
\end{abstract}

\section{Keywords}

General Practice Thinking, Procedural Thinking, Checklist

\section{Introduction}

General Practice is a comprehensive subject with a wide spectrum of diseases. General practitioners (GP) are the main bearer of the initial diagnosis and treatment of the vast number of residents in the community. It is challenging to make a more correct diagnosis timely and reasonable treatment with the least instrument examination in a short time. The reference GPs need to rely on practical experience counts, which will take a long time, and different doctors establish different diagnostic processes. Although rich experience is conducive to diagnosis rapidly, it may also produce inertial thinking and get into confusion. With the development of general medicine in China, the discussion of thinking mode of general medicine is increasing day by day [1] [2]. How to achieve safe initial diagnosis and treatment, to ensure patient safety, has become one of the 
focuses of General Medicine. Description of John Murtagh's General Practice by Murtagh: a general medicine expert in Australia [3] is widely recognized as the most influential publication for general practice and primary health care. Now in its fifth edition, this was regarded as the gold standard reference which covers the entire diseases spectrum in general practice. The book presents early diagnosis and identification of life-threatening diseases due to the undifferentiated problems of the general practice, overlapping physiological, psychological and social factors, and the basic thinking model of general practice based on a large number of experiences and methods (see Table 1) [3]. Medicine is an ever-changing science. As new research and clinical experience broaden our knowledge, changes in thinking mode of diagnosis and treatment are required. This paper refers to the thinking mode of Murtagh, and establishes the process thinking for general practitioners to ensure medical security. Readers can draw on their own experience to make the model work effectively for themselves.

\section{Process Thinking}

The process thinking is to control the overall situation and the key of the things to be completed, and to establish a fixed structural scheme based on the requirements of the overall system [4].

Process thinking focuses on results and final goals, emphasizing integrity and systematization, not local. Murtaghs General Practice is also the thinking process which outlines the thinking steps that general practitioners should consider. Its general diagnosis model follows certain procedure steps by answering those five questions quickly to ensure medical security. A statistical analysis of medical errors [5], submitted by the American Institute of Medicine more than 20 years ago, points out that making mistakes is human nature, and the only way out is to change thinking mode. Building a "no mistakes" workflow and safety concept is the fundamental solution. So workflow and process thinking is very important in medicine [6].

Table 1. Murtagh's general practice [3].

\begin{tabular}{|c|c|c|}
\hline & Question & Interpret \\
\hline 1 & Probability diagnosis & What is the most likely diagnosis? \\
\hline 2 & Serious disorders not to be missed & $\begin{array}{c}\text { Is there a serious disease that will threaten the } \\
\text { patient's life and cannot be missed? }\end{array}$ \\
\hline 3 & Pitfalls (often missed) & $\begin{array}{l}\text { Is there any disease that is easily } \\
\text { neglected in clinical? }\end{array}$ \\
\hline 4 & The masquerades & $\begin{array}{c}\text { Does the patient suffer from diseases that are } \\
\text { easily mistaken for other diseases? }\end{array}$ \\
\hline 5 & Psychological factors & $\begin{array}{l}\text { Does the patient have any other } \\
\text { unexplained problems? }\end{array}$ \\
\hline
\end{tabular}




\section{Steps and Content of the General Practice Initial Diagnosis Model Based on Process Thinking}

No matter what we do, whether in life, leisure or work, there is a sequence of "what to do first, what to do next, what to do last", which is what we call the process. According to this concept, the concrete operation steps of flow thinking are established (Table 2).

\subsection{Is This a Serious Patient?}

It is one of the tasks for general practitioners to judge the high risk of patients with symptoms and adopt different diagnosis and treatment strategies according to the risk degree. For critical patients, the pathophysiological changes of patients must be given preemptive diagnosis to rule out life-threatening conditions; for non-critical patients, the urgency of time does not be emphasized in "stratified titration" diagnosis.

This is different from Murtaghs General Practice, Whether or not to be a critically patient is the result of medical development and medical humanistic progress. In 1991, a medical study at Harvard found that 3 to 4 percent of adverse events were related to hospitalization [7]. The book To Err Is Human, published in 1999, pointed out that more people died of medical errors than traffic accidents in that year, and adverse medical events were the third leading cause of death among American citizens [8]. In September 2019, according to the World Health Organization website: adverse medical events due to unsafe medical care may be one of the top ten causes of death and disability in the world, And up to $80 \%$ of the damage is preventable [9], it sounded the alarm bell for us.

Although general practitioners are more exposed to mild patients in the community, emphasizes the principle of common diseases and frequent diseases

Table 2. Thinking flow [6].

\begin{tabular}{|c|c|c|}
\hline & Thinking flow & Content of thinking \\
\hline 1 & Is this a serious patient? & $\begin{array}{l}\text { Symptoms to judge critical degree (vital signs) } \\
\text { or preemptive examination }\end{array}$ \\
\hline 2 & $\begin{array}{l}\text { What is the main problem } \\
\text { (symptom) of this patient? }\end{array}$ & $\begin{array}{c}\text { True or false symptoms, symptoms } \\
\text { of the eight major factors }\end{array}$ \\
\hline 3 & $\begin{array}{l}\text { What are all the causes covered } \\
\text { by this major symptom? }\end{array}$ & local, adjacent, systemic, and mental \\
\hline 4 & $\begin{array}{l}\text { What is the most likely diagnosis } \\
\text { of the patient? }\end{array}$ & $\begin{array}{l}\text { Common diseases and frequently } \\
\text { occurring diseases }\end{array}$ \\
\hline 5 & $\begin{array}{c}\text { Does the patient have any other } \\
\text { possible problems? }\end{array}$ & $\begin{array}{c}\text { Potentially life-threatening condition (VINDICATE), } \\
\text { adherence to treatment and individuality; } \\
\text { reassurance and explanation }\end{array}$ \\
\hline
\end{tabular}


in their clinical thinking. In fact, all body do not know whether the first visit of patients with common diseases or rare, do not know whether the patient has life-threatening diseases or not, let alone how the patient's disease will evolve. The experienced general practitioners subconsciously think about the severity and risk of each patient's condition at the first visit of patients, then further diagnosis and treatment. But the doctor's experience accumulation may need time and come through malpractice, they can harm the patient's body, even the life. So the process thinking follows the conceptual model of "First do no Harm" and takes "ensuring patient safety" first [10], which is the embodiment of the essential purpose of medicine and the first principle of clinical thinking. Therefore, the process of thinking mode emphasizes early identification of critical patients for treatment and referral.

General practitioners may not have sophisticated instruments and large equipment in the community to determine the severity of the patient. The process thinking points out that the severity is judged by symptoms. National early warning score (NEWS) [11] is now commonly used, and respiration, oxygen saturation, body temperature, systolic blood pressure, heart rate, consciousness are also commonly used. This assessment method is based on the symptoms of vital signs, not instruments and which is easy to obtain in the community.

\subsection{What Is the Main Problem (Symptom) of This Patient?}

The initial diagnosis of the patient should be based on the patient's initial conditions, which is a symptom, not a disease. Process thinking is based on symptom-oriented and conforms to real clinical practice. All subjects, whether general practice or other specialized subjects, are symptom-centered, chief complaint-centered and patient-centered. That is understructure to explore the regular of disease development and treatment strategies. For example, patients with toothache do not have to see doctors in department of stomatology, the pain may be cardiogenic; Chest pain of patients may be reflux esophagitis which is a disease in the Digestive Department; As everyone knows, abdominal pain in patients may be a cardiovascular disease.

First of all, Patients sometimes do not come to hospital with multiple symptoms other than with one symptom. The most important symptom should be selected as the guidance direction. Symptom-oriented should clearly distinguish the main symptoms from false symptoms, and the high risk and low risk of symptoms also should be distinguished with eight factors of symptoms. Applying real symptoms guide the thinking of the next consultation and physical examination for general practitioner. For example, the cause of vomiting blood may be multiple causes, hemoptysis, throat wall bleeding or clotting dysfunction. General practitioners must judge whether the patient is critically ill first, and then whether it is true hematemesis or not, where is the main bleeding site, and finally applying real bleeding symptoms guided next inquired and physical examination. 


\subsection{What Are All the Causes Covered by This Major Symptom?}

Symptoms of the patient often do not directly come from the primary disease. Neither a clinical symptom nor a group of clinical symptoms represents one disease; one disease may have multiple symptoms, while multiple symptoms may be caused by a single disease cause. The complexity of clinical manifestations is the difficulty for general practitioners. The diagnostics listed in the differential diagnosis of a disease is extremely rich [12], and It is a very heavy task for every doctor to remember hundreds of diseases and their manifestations. Therefore, it is extremely difficult for general practitioners to "think something then do it" and "think thoroughly, think deeply and think carefully". This was described in steps 3, 4 of the Murtagh diagnostic strategy, but numerous differential diagnoses are difficult to remember.

A checklist for clinical thinking is an effective approach to deal with this. Taking the principle of "simplicity first" in the list. We reclassified the things for easy memory, set clear checkpoints, and carry out the inspection procedures according to the listed items [13]. The checklist had four key directions based on the principle of anatomical positions (local, adjacent, systemic, and mental) and holistic thinking, which is provided to aid general practitioners to easily memorize and streamline the diagnosis and differential diagnosis steps and thus minimize missed and/or erroneous diagnoses. Checklists fit the principles of mind mapping, but they are simpler and more flexible, for example, Checklist of Causes of chest pain (Table 3) [6].

\subsection{What Is the Most Likely Diagnosis of the Patient?}

A preliminary diagnosis is proposed based on the patient's symptoms, signs and the necessary laboratory tests after analyzing, synthesizing and evaluating the data, then follow the principle of "common diseases, frequently-occurring diseases, monism and wholeness" to verify or revise the preliminary diagnosis [12].

According to checklist above, it provides a systematic overview of the diagnosis, rather than a specific disease. The key physical examination and auxiliary examination should be carried out according to checklist, which makes the direction of differential diagnosis clear, and to broaden the lateral thinking of general practitioners, and maybe reduce the possibility of missed diagnosis and misdiagnosis.

The most likely diagnosis is based on the comprehensive evaluation of the results obtained after the implementation of the above process thinking steps, the exclusion of critical patients, the identification of major problems or symptoms, and a simple and comprehensive list of differential diagnosis directions. This may be more targeted to reduce unnecessary instruments and get a more correct diagnosis with minimal instruments.

Historically, the process of disease diagnosis and treatment is an evolving experience and thinking decision-making. The collection of patient information, the identification of correct symptoms, and the comprehensive analysis of data 
Table 3. Checklist of causes of chest pain.

\begin{tabular}{|c|c|c|c|}
\hline Symptoms & Direction & Location & Causes of diseases \\
\hline \multirow{16}{*}{ Chest pain } & \multirow{12}{*}{$\begin{array}{l}\text { Local organ } \\
\text { disease }\end{array}$} & \multirow{4}{*}{$\begin{array}{c}\text { Cardiovascular } \\
\text { diseases }\end{array}$} & Angina pectoris, myocardial infarction \\
\hline & & & Aortic dissection \\
\hline & & & Pulmonary embolism \\
\hline & & & Cardiomyopathy, pericarditis \\
\hline & & Respiratory diseases & $\begin{array}{l}\text { Spontaneous pneumothorax, hemothorax, empyema, pneumonia, } \\
\text { lung cancer, etc. Pleuritis, pleural neoplasms. }\end{array}$ \\
\hline & & Mediastinal diseases & Mediastinitis, mediastinal tumor, hiatal hernia, esophageal carcinoma \\
\hline & & & Dermatitis, subcutaneous cellulitis, myositis, etc. \\
\hline & & & intercostal neuralgia \\
\hline & & Chest wall disease & Chest and abdominal wall suppository superficial phlebitis \\
\hline & & & Herpes zoster, etc. \\
\hline & & & Costal cartilage inflammation, rib fracture, cervical or thoracic diseases, etc. \\
\hline & & Spinal spine & Vertebra disease can lead to precardiac pain, known as "cervical angina" \\
\hline & \multirow{2}{*}{$\begin{array}{l}\text { Adjacent organ } \\
\text { diseases }\end{array}$} & \multirow{2}{*}{ Abdominal diseases } & Reflux esophagitis, etc. \\
\hline & & & Abscess, liver abscess, splenic infarction, liver cancer, etc. \\
\hline & Systemic diseases & & Acute leukemia, multiple myeloma, ankylosing spondylitis \\
\hline & Mental disorders & Cardiac neurosis & Cardiac neurosis, etc. \\
\hline
\end{tabular}

are all related to clinical experience. In some cases, it is core skills. The level of clinical experience determines that whether the evidence is reliable, that whether the evidence can be well applied in the process, and which specific thinking mode to choose and how to follow the process to diagnose and treat diseases [14].

\subsection{Does the Patient Have Any Other Possible Problems?}

As a general practitioner, the psychological factors need to be taken into account, so the workflow thinking mode in this paper also involves psychological factors. But in addition to psychological factors, clinical uncertainty, need dynamic observation.

The initial diagnosis has a subjective element. We must be constantly verified and revised until the more correct diagnosis is gotten finally. After giving the necessary treatment based on primary diagnosis, therapeutic effect of dynamic observation is one of the ways to validate our preliminary diagnosis correct or not. If the result is bad, we should re-examine treatment compliance, individuality and the correctness of diagnosis and review some check items, in order to 
provide reliable basis for validation diagnosis.

Even so, the clinical information of patients in general practice is large, and the collection of patient data is difficult to be comprehensive and reliable. In addition, humans are born with various thinking defects, so it is not easy to make a correct diagnosis in a short time. Therefore, dynamic observation is necessary. Even if the patient leaves the hospital, due to the uncertainty of clinical thinking, we need to have a dynamic observation process, dynamic observation is as important as drugs and laboratory tests, or even more important. Especially potential life-threatening conditions (vascular disease, inflammatory disease, neoplasm, degenerative/deficiency, intoxication, congenital disease, autoimmune disease, trauma, endocrine disease; VINDICATE) [3].

Patients often have different degrees of anxiety, worry, and various ideas about their own disease diagnosis and prognosis. General practitioners should first stand on the patient's position, empathize to understand the patient's situation and mood, show sympathy for the patient, give patients support from the medical and psychological perspectives, eliminate the patient's doubts and worries through comfort and explanation, and correct the attitude, belief and understanding of the patient that is not conducive to health.

\section{Conclusion}

Process thinking is to summarize the perceptual knowledge and clinical experience into rational knowledge and thinking methods, and is finally presented in an effective workflow according to the principle of clinical thinking. Process thinking begins from the symptoms and the overall perspective to widen the lateral thinking of general practitioners, which is based on the principle of "patient safety first" [15], and let general practitioners have common patterns of initial diagnosis. The doctors don't provide different initial diagnosis way due to different doctors and hospital, and accelerate the young general practitioners training process and ensure patients safety.

\section{Limitation}

A limitation of this study was that there are no data of clinical applications to support the above conclusions. Thus, a prospective study is in progress to test the utility of the proposed diagnostic scheme.

\section{Author Contributions}

Jianguo Li had the idea for the article, Xurui Li wrote the article, Hui Guo performed the literature search, and Jianguo Li was the guarantor.

\section{Conflicts of Interest}

The authors declare no conflicts of interest regarding the publication of this paper. 


\section{References}

[1] Qian, Y.M., Guo, J., Qian, F.H., et al. (2015) Study on the Training of Clinical Divergent Thinking in General Practitioner. Shanghai Medical \& Pharmaceutical Journal, 2015, 62-64.

[2] Tian, S.L., Yin, L., Tan, W., et al. (2017) Introduction to General Resident Standardization Training in Clinical Thinking Ability. China Continuing Medical Education, 2017, 3-4.

[3] John, M. and Jill, R. (2020) John Murtagh's General Practice. Australia: McGraw-Hill Australia Pty Ltd.

[4] Huang, Y.C. (2016) Internet Operation. Vol. 9, Publishing House of Electronics Industry, Beijing, 69-79.

[5] Kohn, L.T., Corrigan, J.M. and Donaldson, M.S. (1999) To Err Is Human: Building a Safer Health System. National Academy Press, Washington DC.

[6] Qi, H., Shen, Z., Guo, H. and Li, J. (2020) Discussion on Homogenization of Emergency Clinical Decision. Open Journal of Internal Medicine, 10, 302-310. https://doi.org/10.4236/ojim.2020.103031

[7] Brennan, T., Leape, L., Laird, N., Hebert, L., Russell Localio, A., Lawthers, A.G., et al. (1991) Incidence of Adverse Events Andnegligence in Hospitalized Patients: Results of the Harvard Medical Practice Study I. The New England Journal of Medicine, 324, 370-376. https://doi.org/10.1056/NEJM199102073240604

[8] Kohn, L.T., Corrigan, J.M., Donaldson, M.S. and Institute of Medicine (US) Committee on Quality of Health Care in America (1999) To Err Is Human: Building Asafer Health System. National Academy Press, Washington DC.

https://doi.org/10.17226/9728

[9] World Health Organization (2019) Patient Safety. https://www.who.int/zh/news-room/fact-sheets/detail/patient-safety

[10] Di Cuccio, M.H. (2015) The Relationship between Patient Safety Culture and Patient Outcomes: A Systematic Review. Journal of Patient Safety, 11, 135-142. https://doi.org/10.1097/PTS.0000000000000058

[11] Jones, M. (2012) NEWSDIG: The National Early Warning Score Development and Implementation Group. Clinical Medicine Journal, 12, 501-503. https://doi.org/10.7861/clinmedicine.12-6-501

[12] Wan, X.H. and Lu, X.F. (2018) Diagnostics. People's Health Press, Beijing, 587-591.

[13] Gawande, A. (2017) The Checklist Manifesto. How to Get Things Right. Vol. 10, Beijing Union Press, Peking, 46-56.

[14] Zhao, Y.Q. and Zhao, G. (2018) The Influence of Clinical Decision from on the Development of Medicine. Medicine and Philosophy, 39, 1-3+13.

[15] Guo, H., Zhao, Q. and Li, J.G. (2019) Discussing How Medical Humanities Enter into Clinic from the Angle of Clinical Thinking. Medicine and Philosophy, 40, 17-20. 